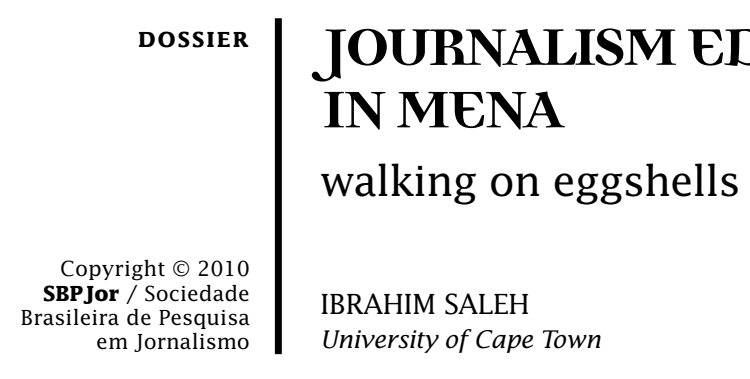
ABSTRACT One of the most contradictory media scenes is the Middle East \& North Africa (MENA), which is a reflection of its rather contrasting, and troubled societies that suffer from the negative effects of imposed democracies, and the internal tripled-edged syndromes of illness, poverty and illiteracy. Using the metaphor of walking on egg shells, the author discusses the depiction of the perplexity of the MENA in which societies just never knowing when they will run afoul of some unknown rules, expectations, and even suffering more when they do. Such rhetoric resonates with how the public in MENA has become victims of the Borderline Personality Disorder (B.P.D.).

Key-words: Journalism Education, Middle East and North Africa (MENA), civil liberties, Coercive Societies and National Development.

\title{
INTRODUCION
}

Could you be some redemption

Could you be some relief

Could you be a safe haven

Do you promise to believe

When I tell you these stories

Every pain and hard won glory

Bear witness to a life

Lived with good intentions so far

So believe me, heal me

Believe me, it's all true.

-Carrie Newcomer, "Bearing Witness"

Using the metaphor of walking on egg shells, is a depiction of the perplexity of the Middle East \& North Africa (MENA) in which societies just never knowing when they will run afoul of some unknown rules, expectations, and even suffering more when they do. Such rhetoric resonates with how the public in MENA has become victims of the Borderline Personality Disorder (BPD), and is often subject to bewildering mood shifts and unpredictable behaviors to displace their endless internal problems, and the worries about the other (Mason \& and Kreger, 1998). 
At a time when the Arab region is full of potential for capacity-building, social unrest, political agitation and poor civil liberties are still plaguing the population. The status of journalism education is low, preoccupied by many other vital issues, and yet the lack of it is detrimental to civic engagement and the absence of a valid curricula that reflects the diversity of the twenty-two Arab countries and also lacking any real standards for critically assessing the journalism education landscape.

The current journalism education in many parts of the region is a direct result of the weak economic base, heavy political patronage, cultural fragmentation, centralized geographic concentration, decreasing credibility and low prestige of journalism. Besides, laws and regulations are not clearly stated with regard to safeguard the journalism education and other professional values (Saleh, 2010). Hence, it is rational to relate the internal socio-political and economic problems with the external cut-off from the world, which characterizes the hybrid curricula in the Arab region. This situation is made even more complex by a combination of heavy consumerism, religious conservatism and military presence that limited the role of journalism programs into places of PR centers (Saleh, 2009).

Indeed, (MENA) is one of the most contradictory media scenes, which is a reflection of its rather contrasting, and troubled societies that suffer from the negative effects of imposed democracies, and the internal tripled-edged syndromes of illness, poverty and illiteracy.

Democracy is almost a synonym of equality; however the military elite often obstruct state-directed reformism with the pretext of defending liberty, and the efficacy of market forces (Saleh, 2008). Besides, the obscene of well-oriented state, the bourgeois, and the civil society is either demolished completely or is suffering from exacerbating inequality. In such context, policies are often made on the hoof, but the civil society in the Middle East and Africa must also be blamed for their persistence to marginal instead of offering the society through its key players a deep guesstimate about what they know (AINA, 1997). It is thus very crucial to give the way to a leader cadre of public intellectuals, who have experience, knowledge, yet command the authority to challenge the current corrupted environment.

\section{Setting the Scene:}

During the second half of the $X X^{\text {th }}$ Century, the MENA region aimed at unifying the general framework of its respective legislative processes, particularly through multilateral cooperation within the League of Arab 
States. In 1981, at the Second Conference of Arab Ministers of Justice in Sana'a, the capital of Yemen, the "Sana'a Strategy" unified the domestic legislation through a series of integrated codes, including civil law, civil law procedures, penal law, penal procedures, juvenile law, prison standards, combating information technology crime, and matters related to personal status, and judicial organization and regulation (Saleh, 2009).

The League of Arab States also formed a committee to unify legal and judicial terms, structures, and processes to achieve a more integrated and harmonized legal system. Concurrently, to implement the recommendations of this committee, the League of Arab States also established the Arab Center for Legal and Judicial Studies in Beirut, Lebanon.

In the mean time, there is a disconnection between journalism education, and governance that could have offered a valid local model, by linking the public agenda with all its aspirations, and disparities of grassroots in the troubled societies with the state. This has also could have improved the current poor local governance in many parts of the Arab region. However, this basic right needs an independent free media and an appropriate political culture context to function as a catalyst and a refuge for elevated conversation that makes the Arab public become politically informed, and to engage them in the decision-making process of their present and their future.

Undoubtedly, this comes at a time of real convergence, as well as an emerging globalization of human conscience and culture, including human right. In 1999, the Human Development Report a "globalization of human face," especially that the progressive development (human development and human right development) are intertwined (HD Report 2000). It is thus impossible to assess, and overcome the current challenges without examining three key domestic conditions: the persistence of the degree of democracy, the degree of social divisions, and the level of economic prosperity.

Socioeconomic development, emancipative cultural change and democratization constitute a coherent syndrome of social progress, a simple reality that was not properly addressed by many scholars. Hence, the cornerstone of this paper is in its attempt to broaden human choices, which increases individual resources; rising emancipative values strengthen people's subjective orientation towards choice; and democratization provides legal guarantees of choice by institutionalizing freedom rights.

Analysis of data from the World Values Surveys demonstrates that the linkage between individual resources, emancipative values and 
freedom rights is universal in its presence across nations, regions and cultural zones; that this human development syndrome is shaped by a causal effect of individual resources and emancipative values on freedom rights; and that this effect operates through its impact on elite integrity, as the factor which makes freedom rights effective

One has to contextualize the notion of "Identity Crisis" that explains the conflict of self and society, which is coined with one of the most famous psychoanalyst of the 20th century, Erik Homberger. In general, Erickson's Theory of Human Development plays a major role in all human and psychological development studies and theories. It is thus used as a framework or map for understanding and identifying what issues/conflicts unresolved lead to current behavior and preparing for the stages to come.

The main hypothesis here is the link between the phased process of development with the pace and dynamics of media direction tendencies toward the empowerment of civil societies. For example, Levy (1967, p. 207) "as time goes on, they and we will increasingly resemble one another because the patterns of modernization are such that the more highly modernized societies become, the more they resemble one another." Modernization through media is an irreversible process, which cannot be stopped. Hence, the Middle East will not be able to resist the impetus toward global modernization.

Hence, the basic concern here is with assessing the decision-making process, as well as the related political "media-tization" of the process of legitimizing and enforcing the rule of law, while observing the civil liberties and local governance in these developing societies.

This thesis goes hand in hand with the query of mapping the level of endorsement of freedom of expression, as well as the advocacy of transparency, diversity, and integration in Internet, while covering social integration, economic transformation, and vital regional issues (such as the Nile Basin in Africa and the Arab-Israeli Conflict in MENA). The pace and dynamics of local media convergence (Internet) must be addressed towards fulfilling the fundamental human requirements, self-reliance, and the development of self-government by local society, and enhancing environmental quality.

Indeed, in coercive societies, where civility is almost nonexistent, there is no leader liking the sound of the truth, and often let it murmur just outside our consciousness without listening or revisiting our intact ideas and beliefs, though our careful attention, and facing our worries and fears might lead us toward wisdom, health and clarity as a condition of not just our integrity, but also our progress towards real local governance. 
The absence of well-oriented state and presence of effective media will always have a weak civil society, and generally a vulnerable societal fabric that is either demolished completely, or at least suffers from exacerbating inequality. Indeed, there is an obvious clash between empowering civil society and sound media structure on one hand, and the socio-political and economic context of the Middle East. In almost all the time, speaking truth to authorities is very dangerous because politicians contradict their acclaimed care and dust for authenticity. Hence, media and communication in the region suffer from the milieu of setback in many aspects that vary from finance, resources, and technology, but most importantly the obscene for real functionality of media that make the process a tamed journalism or even just protocol news.

As mentioned in the latest report of "Human Development: Challenges to Human Security in the Arab Countries," there are obvious negative differences indicating a deterioration in the scene. In that regard, the average institutional change for the Arab countries is (-0.02), and there is no evidence of any overall improvements in governance. Hence, the period (1996-2007) marks deterioration. For the low income countries, the institutional reform challenge resides in Government Effectiveness, Political Stability and Control of Corruption witnessed deterioration, while for the lower middle income countries a small improvement in political stability is noticeable; which can explain in the light of poor start of these countries (Algeria, Egypt and Iraq).

And even in the upper middle income countries recorded the limitations of the rule of law indicator, and very marginal progress on 'Voice and Accountability', which remains a significant priority for their reform efforts.

It is only popular democratic movements that emerge from below can enhance a real progress of self-empowerment to sustain a peopleoriented progress. In contrast, the top down imposed movements are always beleagued by domestic discontent, and external pressure. It is almost a rule that such structures are buffered by economic crisis, deep cleavage, which means short evidence. Accordingly, the development of human, or people centered paradigm that could certainly emphasize the progress role of civil society (Korten 1990; Clark 1991).

Barrington Moore (1966:418) stated that the town dwellers are indispensable in the growth of parliamentary democracy, which frames the simple fact that no bourgeois, means no democracy. As the weak civil society will hinder or even obstruct democratic consolidation. The civil society needs parallel levelling: The first includes the creation of healthy 
environment for change to inspire or revisit the social contract between the government and the publics, and the second involves constitutional enhancement of human rights, and democratization (Saleh, 2008).

This allows people to share a bottom up, or a self-reliant approach to enhance the society's self-empowerment, which certainly means a mix of developing sense of agency, or efficacy on the one hand, enabling the deprived groups to shape the decisions affecting their lives, by expanding their autonomy, resources and capability. Nevertheless, the real problem lies in the failure to assess or predict the status quo of literally everything.

The region needs better governance focuses on the stipulation of societies to become more productive, safe guarding the political order, by fostering adequate infrastructure, calculable laws and administrations. But in reality, this clashes with the dim reality of heavy-handed regulation of civil society, by suspicious autocrats who block grassroots initiatives and directs people to flee into underground societies that are both radical and anarchic.

It is always assumed that civil society needs a disciplined and responsive political culture that openly makes decisions, and whose officials hold an accountable for their actions. Accordingly, there is urgency for an effective media that that monitors government performance \& publicizes abuse, and advocate community participation. Such a structure is dependent on pro-active internventionalist government facilities, though most of the current political cultures lack irrespective of will, and the basic socio-political and economic climate.

'False Starts' could be one of the reasons for what we are currently witnessing because democracies in the region have been imposed by colonial and semi colonial rule towards the end of the 19th century. As the imperial powers transplanted institutional models from the metropolis of the host cities with the political traditions, cultural linguistic diversity lacked organic connections.

After Independence, the military regimes in the regions adopt the same strategies, centralized powers, neutralized opponents, and ignored the widespread of poverty and hampered the consolidation of effective states. As a result, many societies lack proper education, limited skilled personnel, drastic erosion of civil services, decline in salaries, and increasing in mass poverty have all gathered to instigate struggle over scarce resources threatening the whole state apparatus in the region.

In theory media was supposed to play a crucial role in stipulating social progress, yet it has only played a role to promote for state 
victories, especially in their current overwhelming control through media monopoly (Wilcox, 1982, 200-32), and practicing all their tactics of work hostility environment through licensing, subsidies. Hence, in reality most of the media systems follow the 'patrimonial mechanisms,' governance is based relies on a coterie of regional and organizational notables (Sandbook \& Barker, 1985). As such, most of the institutions are predominately characterized by factional maneuvering, clientalistic relations, and the exclusion of middle class, which means a chain of personal loyalties, and coercion.

In addition, 'prebendalism' is very common, refers to the political behavior in which individuals compete for public offices to use them for personal benefit (Joseph, 1987,56-57).

It is rational to find clientalism and prebendalism is mutually supportive and interconnected. Obtaining and maintaining clients need prebendal offices to ensure distribution for power and share interest among their circles. In this regard, unsecured rulers augment the capacity to reward followers and punish actual and potential opponents.

As articulated sharply and clearly by Umbadda (1989, 22): "Confinement of top professional jobs to inept/incomplete relations and political supporters leads to the waste of talents and demoralization and exodus of competent staff." This acute dilemma in the region is projected through patronizing wasteful and fosters incompetence and unpredictability, however if this patronage is declined more, the emphasis will be directed oppression. For example, the Egyptian Radio and TV Union (ERTU) avoids any lay-off for the $(50,000)$ personnel to avoid social agitations.

There is an urgent need to voice out our inner voices and put to an end the current self denial, no matter how confused, self-doubting or ambivalent we are. I perceive the current happening as a syndrome of Borderline Disorder in the media apparatus in the region. I also see the need for an empowered civil society and sound communication as the only means of stop walking on eggshells!

The research paper aims to find new ways or even visit other models that emphasize the progressive role of civil society through media that could allow people to share a bottom-up communication that can resonate in the well-fare of the society.

As mentioned by (Achebe, 1987, 45) that the real dilemma remains in the ambiguity of what's up and what's down, though there is a collective sense of being fed up of everything, and a growing sense of alienation within societies in the region. 
The way is difficult to attain these basic goals, and the current autocrats are always fighting and punishing a serious attempt of liberating the media. This situation gave way to displacement of the discontented public into unregulated informal underground sectors, and illegal activities like different kinds of extremism including religious, social and human trafficking.

The region suffers from a general phenomenon of 'crisis of governance' a term mentioned by (Dumont, 1996, 65) that has resulted from the 'etatist' approach and the weak indigenous business class, and the professed commitment to social equality!

Indeed, the patriotism and the acute external threat have substituted the self-discipline of rationalist elite for the extreme discipline of a strong vigilant civil society.

Having said so, the research paper draws a metaphor of the walking on eggshell to address the key domestic issues of social inclusion, democracy and economic setting that have shaped the nature of media and color its performance with a borderline syndrome.

Such transition of societies of imposed democracies involves a number of principle components such as the official recognition and maintains of civil and political rights, and the support for legal rights of opposition as well as the stipulation of interest groups.

Such democratic consolidation involves strengthening the organizational coherence, autonomy and the popular support of institutions to publicize abuse. Hence, without a civil society that is willing and able to resist the current authoritarian systems, there will only cosmetic facade designed for foreign consumption.

The emergence of strong and sound civil society is a pre-condition for realizing political parties, free competitive environment, and the enforcement of the rule of law. However, civil society needs a dense network of autonomous associations, and building social consensus on the democratic values. A priority is to deal with the endless domestic problems ranging from fractions in some countries like Lebanon, or religious agitations as in Egypt, and ethnic and tribal issues as in Morocco, $\&$ Iraq, which emphasizes that the media endorsement of such cleavages are misconceived inside and across societies.

As stated by the migraine political scientists and activist Claude Ake: " rights have real significance for our lives are usually taken, not given with the cooperation of those in power, but without it if necessary (Ake, 1987:11).

Strengthening civil society through collective self-empowerment can 
people address their pressing needs and problems on their own, and mobilize demoralized government bureaucracies.

Among the many challenges facing good governance in MENA is the threat to power structures because regional governments want to maintain their manipulation their dominance, and never allow any expansion of civil liberties to ensure being followed. The reason is obviously that well informed people are automatically empowered, and become agents of change in societies (W. Maathain quoted in Topouzis, 1990, 31).

\section{Discussion \& Conclusion}

A dilemma of inequality within the same society to what I consider a new kind of colonization by the Patron states that resulted with severe repercussions on the journalism education curricula because of the continuous process of legitimizing coercion, political PR-ization, and the use of social taboos block investigative reporting and entrapped the field into contrasting odds and vicious circles of liberalization and deliberalization. In addition, the ministers of information throughout the years execute the agenda of the state to control journalism curricula and shape their content, by enforcing harsh laws with imprisonment and physical violence. Though there is new means of expression have proliferated between the Internet and other mobile communications, yet the 'Patron State' through the ministries of information in many of the Arab states and its orchestrating role and influence over the ministries of higher education have regulated the freedom of press, and expression, blocked the emerging activism of the expanding population of a predominately poor, illiterate youth; and offered a hybrid journalism curricula through a prism of individual and collective humiliation and resentment.

It is thus trivial to think that journalism education could be a communication tool without empowering it with the capacity to stipulate good governance through governments' effective assistance. The journalists and many o the journalism students are very frustrated with the results of poor governance. The recruitment, capacity building and incentives of employees all need attention. Nevertheless, weak governance imbroglio has given ammunition to the two entrenched forces for censorship within the journalism education fabric, namely; the authoritarian regime and the Islamic fundamentalist opposition. Both would prefer to silence their critics though the evincing outrage through displacement, the authoritarian regime diverted the attention from the local political and military failures and bolstered the religious credentials against the Islamists who seek to unseat them. 
I believe that journalism education in MENA could only be leveled through the emphasis on two competent. First, the focus should be directed towards the level of citizens' participation in public life within political parties and outside them too, where journalism solves problems. The second focus should be on engaging the public in timely issues to foster rational public discussions.

Sticking to the self-motivated private self-interests in journalism curricula rather than the national well being will never allow the public a chance to voice their problems and concerns. It will always let the masses be at least relatively powerless and voiceless. There is an urgent need for supporting the process that promotes change and aids education and critical thinking as well as the other projects that explicitly help people learn to coordinate and organize opposition to vested interests. Empowering the civil liberties can gradually help reduce or end government control of the public media and of information flow.

It is worth mentioning that establishing a new set of institutions to grapple with this reality, and new training methods to engage people in national self-interest and identity-construction could put to end the current dilemma. But priority should be given to re-evaluating the journalism education curricula in the Arab region in both private and public schools and departments of journalism, and push for the legitimate right of participation in the decision-making process, and be of use for leaders and decision-makers to implement change without turmoil, with a progressive understanding of peace and human rights as a way of reclaiming the Arab identity and pride.

In conclusion, there is an obvious robust environment that is full of vigorous competition of ideas that attempt to cater the needs of the public, but does this context entails for multiplicity of views, and space for observing the government performance, as well as checking the level of corruption and abusive behavior of different constituent in the society. In a successful democracy, media usually carry the four dimensions of governance: First, authority of institutions and actors within the arena to exercise power. Second, transparency of the decisionmaking process and the actual decisions made and actions taken, while the third includes accountability of the government, whether it is to the electorate, the judiciary, civil society or other actors. Fourth, the capacity and effectiveness of institutions are reflected in the way they exercise their authority.

In the general scheme, media in MENA states suffer from the lack of capacity to perform their roles. Besides, media lack transparency and 
accountability, and disregard the demands from the public. Hence, the different mass media, especially with the possible effects of new media, a more effective role for civil society organizations, needs to be improved.

There is public frustration with the results of poor governance. Besides, the economic growth and poverty reduction remain major challenges. But beyond remuneration, there are problems with management structure, human resources, staffing and career paths. The recruitment, capacity building and incentives of employees all need attention.

\section{| BIBLIOGRAPHY}

Achebe, C. (1987). Anthills of the Savannah, London: William Heinemann.

Aina, T. (1997). "The state and civil society: Politics, government, and social organization in African cities," in C. Rakodi (eds.) The urban challenge in Africa: Growth and management of its large cities, Tokyo: United Nations University Press.

Ake, C. (1987). "The African Context of Human Rights,' Africa Today," vol.34, $\mathrm{n}^{\circ} 1 / 2$, p.5-12.

"Arab Human Development Reports (AHDRs): Challenges to Human Security in the Arab Countries," UNDP/AHDR calculations based on World Bank Governance Indicators, 2008,http://www.arab-hdr.org/

Clark, J. (1991). Democratizing Development: the role of Voluntary Organizations. West Hartford: Kumarian Press.

Czempiel, E.-O. (1992) "Governance and Democratization, "in James N. Rosenau and Ernst-Otto Czempiel (eds) Governance without Government: Order and Change in World Politics. Cambridge: Cambridge University Press, p250-271.

Enterline, A. J., \& Greig, J.M. (2008). "Against all Odds? The history of imposed democracy and the future of Iraq and Afghanistan," Foreign Policy Analysis, 4, 321-347.

Drotner, K. (1992). "Modernity and Media Panics, "in M. Skovmand and K.C. Schrøder (eds.) Media Cultures: Reappraising Transnational Media. London: Routledge, p42-62.

Joseph, R. (1987). Democracy \& Prebendal Politics in Nigeria: The Rise and Fall of the Second Republic. Cambridge: Cambridge Press.

Korten, D.C. (1990). Getting to the 21st Century: Voluntary Action \& the Global Agenda. West Hartford: Kumarian Press

Levy, M. Social Patterns and Problems of Modernization. (Englewood Cliffs, New Jersey: Prentice-Hall, 1967), pp. 189-207.

Mason, P. T. \& and Kreger, R. (1998). Stop Walking on Eggshells. Oakland: 
New Harbinger Publications, Inc.

Moore, B. (1966). Social Origins of Dictatorship and Democracy: Lord and Peasant in the Making of the Modern World. Boston: Beacon Press.

Rosenau, James N. (1992), "Governance, Order and Change in World Politics" in James N. Rosenau and ErnstOtto Czempiel (eds) Governance without Government: Order and Change in World Politics, Cambridge: Cambridge University Press, p.1-29.

Saleh, I. (2008)." Sitting in the Shadows of Subsidization in Egypt: Revisiting the Notion of Street Politics," Journal of Democracy and Security, Philadelphia: Routledge, Vol. 4:1-24.

(2009). "Media Literacy in MENA: Moving Beyond the Vicious

Cycle of Oxymora, "Mapping World Media Education Policies, Latin American Scientific Journal of Media Education

Comunicar, Comunicar, Vol. 32, no. 1. (Feb.).

(2010). "Journalism Education in Egypt: Politically Hazed and Socially Confused", in Journalism Education in Countries with Limited Media Freedom, EDITED BY Beate Josephi, Peter Lang Publishing, Inc, NY: USA.

Skovmand and Kim Schroeder (London: Routledge, 1992), 42-62.

Sandbook,J. \& Barker, R. (1985). The Politics of Africa's Economic Stagnation, Cambridge: Cambridge University Press. Topouiz, D. (1989). "Guinea: Conte"s Challenge," Africa Report, Vol.34, no.p38-41. Wilcox, D.L. (1982). "Black African States," in J.L. Curry \&J.R. Dassin, eds. Press Control Around the World, New York: Preager, p.209-32.

Topouzis, D. (1990). "Wangari Maathai: Empowering the Grassroots," Africa Report, vol.35, no.5, p31-32.

Umbadda, S. (1989). "Economic Crisis in Sudan: Impact and Responses, "Paper Delivered at the Conference on Economic Crisis and Third World countries, Kingston, Jamica,3-6 April.

"United Nations Department of Economic and Social Affairs. Division for Sustainable Development," Documents: Sustainable Development Topics. 2009 Retrieved May 12, 2009 from the World Wide Web: http://www.un.org/esa/dsd/resources/res_docusdt.shtml.

Ibrahim Saleh is Convenor of Political Communication at the Centre For Film \& Media Studies, University of Cape Town (UCT); Chair of the Journalism Research and Education Section, \& Chair of Regionalisation and Membership Committee in the The International Association for Media \& Communication Research (IAMCR);Co-founder of the Arab-European Media Observatory \& Global Partner Organization of the UN Alliance of Civilization Media Literacy Education Clearinghouse. E-mail: Ibrahim.Saleh@uct.ac.za, Isaleh@aucegypt.edu,jre09is@gmail.com or librasma@gmail.com 